\title{
Determination of Spiramycin and Oxytetracycline in binary mixtures by novel spectrophotometric methods with and without regression equation
}

\section{Original Article}

\author{
Afaf Abou El Khair, Hanaa Saleh ${ }^{a}$, Magda El Henawee ${ }^{a}$, Neven Ahmed ${ }^{b}$ and Emad M. \\ Hussien $^{b^{*}}$ \\ ${ }^{a}$ Faculty of Pharmacy, Zagazig University, Zagazig, ${ }^{b}$ National Organization of Drug Control \\ and Research (NODCAR), Giza, Egypt.
}

\begin{abstract}
Spiramycin (SPI) and oxytetracycline (OTC) are widely used antibacterial drugs. Thus, a great attention has been focusing on the development of a simple and selective analytical procedure for fast analysis of these compounds in a binary pharmaceutical mixture. Herein, we report four simple and reproducible spectrophotometric methods for determination of SPI and OTC in a binary mixture and in veterinary pharmaceutical formulations. A ratio difference (RD) based on the difference in the amplitude of the ratio spectra and dual wavelength methods were proposed for sensitive and selective determination of SPI in presence of OTC. Furthermore, Constant Value and Concentration Value based spectrophotometric methods were suggested for simultaneous determination of SPI and OTC in a binary mixture. The methods were successfully applied for the determination of SPI and OTC over the concentration range from 4.0 to 36.0 $\mu \mathrm{g} \mathrm{mL}^{-1}$ and from 2.0 to $32.0 \mu \mathrm{g} \mathrm{mL}^{-1}$, respectively. The proposed methods were validated according to the International Conference on Harmonization (ICH) guidelines. The methods are accurate $(100 \pm 1 \%)$, precise $(\% \mathrm{RSD} \leq 1.5)$ and costeffective for determination of SPI and OTC in binary mixtures.
\end{abstract}

Key Words: Concentration value, Constant value, Dual wavelength, Oxytetracycline, Ratio difference, Spectrophotometry, Spiramycin.

Received: 22 September 2019, Accepted: 18 October 2019

Corresponding Author: Emad M. Hussien, National Organization for Drug Control \& Research, P.O Box 29, Giza, Egypt. Tel.:: +2023749 6077, E-mail: emadhussien@yahoo.com

ISSN: 1110-0930, xxx 2020 Vol.58, No. 1

\section{INTRODUCTION}

Spiramycin (Figure 1) is a macrolide antibacterial drug which is used to treat susceptible bacterial infections. It has also been used in the protozoal infections cryptosporidiosis and toxoplasmosis ${ }^{[1]}$. Spiramycin is a mixture of basic antimicrobial substances produced by the growth of Streptomyces ambofaciens and consistes of spiramycin $\mathrm{I}\left(\mathrm{C}_{43} \mathrm{H}_{74} \mathrm{~N}_{2} \mathrm{O}_{14}, \mathrm{MW}=843.1\right)$ (about 63\%), spiramycin II $\left(\mathrm{C}_{45} \mathrm{H}_{76} \mathrm{~N}_{2} \mathrm{O}_{15}, \mathrm{MW}=885.1\right)$ (about 24\%) and spiramycin III $\left(\mathrm{C}_{46} \mathrm{H}_{78} \mathrm{~N}_{2} \mathrm{O}_{15} \mathrm{MW}=899.1\right)$ (about 13\%) $)^{[2]}$. Oxytetracycline, on the other hand, is a tetracycline derivative which has a pharmacological action similar to that of tetracycline (Figure 1) ${ }^{[1]}$. Although spiramycin is produced by some pharmacopeias as a reference standard ${ }^{[3]}$, there is no pharmacopeial method that can be followed for determination of spiramycin in veterinary dosage forms.

Several non-official analytical methods, however, were reported for the assay of SPI and OTC. These methods include liquid chromatography ${ }^{[4-8]}$ and spectrophotometric methods $^{[9,10]}$ for the assay of SPI; and liquid chromatography ${ }^{[11-17]}$, thin layer chromatography ${ }^{[18,19]}$, spectrophotometry ${ }^{[20,21]}$ and electrochemical methods ${ }^{[22]}$ for the assay of OTC. A densitometic method was reported for simultaneous determination of SPI and OTC in a binary mixture ${ }^{[23]}$. The proposed method uses a mobile phase which consists of environmentally unfavourable solvents. Additionally, the desitometric chromatogram that shows semiltaneous separation and determination of SPI and OTC was not displayed.

In this his work, we report new simple and reliable spectrophotometric methods for the determination of SPI and OTC in a mixture without the need of separation or sophisticated manipulation steps. The Constant Value and Concentration Value methods use a normalized divisor which could be calculated mathematically to get a plateau region through which the compound can be determined and not affected by any change in the wavelength. Concentration value is considered as a new approach in spectrophotometry because it is the first spectrophotometric method that determines the concentration of the drugs 
without using regression equations, where the analysis solely depends on the spectral representation rather than the calibration curves ${ }^{[24]}$. Also, in the ratio difference method, the difference in the amplitude between two points on the ratio spectra of a mixture was found to be directly proportional to the concentration of the component of interest; independent of the interfering component.
Additionally, a dual wave length method was used for the determination of one component in presence of the other.

The proposed methods were successfully applied for the simultaneous determination of SPI and OTC in laboratory prepared mixtures and in pharmaceutical dosage form.
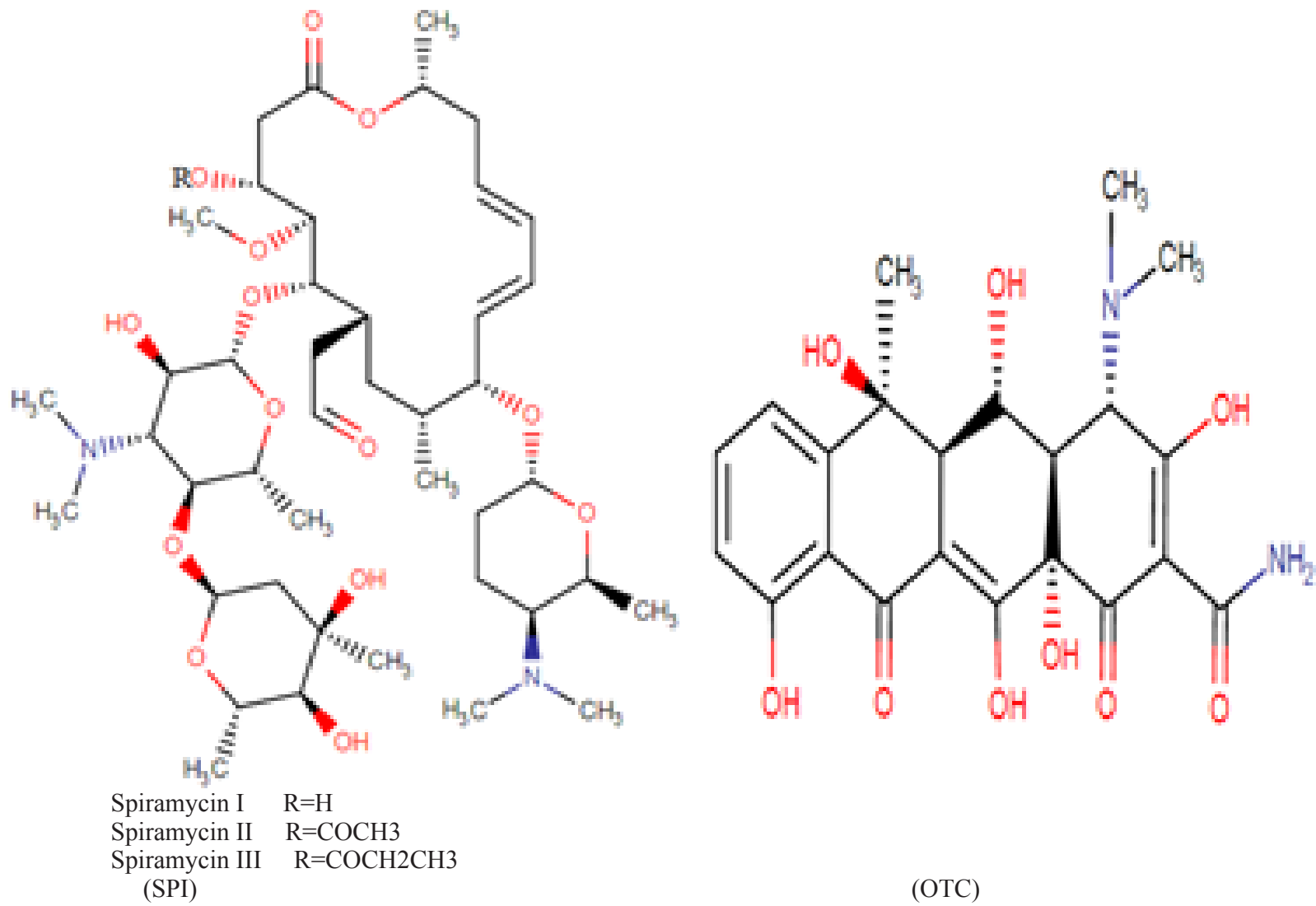

Fig 1: Chemical structure of Spiramycin (SPI) and Oxytetracycline (OTC).

\section{Experimental}

\subsection{Apparatus}

All spectrophotometric measurements were carried out using Shimadzu UV-1601 PC spectrophotometer (Kyoto, Japan) provided with two matched 1-cm quartz cells and spectroscopy software version (2.21). The spectral band width is $0.1 \mathrm{~nm}$ and the scanning speed is $2800 \mathrm{~nm} / \mathrm{min}$.

\section{$2.2 \quad$ Materials}

\section{Pure standards}

Spiramycin (purity $=98.80 \%$ ) was obtained from Henan Topfond Pharmaceuicals Co., Ltd (Zhumadian, China). Oxytetracycline $\mathrm{HCl}$ (purity $=97.60 \%$ ) was obtained from Pharma Swede, $10^{\text {th }}$ of Ramadan, Egypt.

\section{Pharmaceutical formulation}

Arcospirox $^{\circledR}$ powder (batch number: 100716/A) contains $107.9 \mathrm{mg}$ (OTC) and $71.8 \mathrm{mg}$ (SPI) per 1.0 gram was obtained from Arco Pharma, Cairo, Egypt.

\subsection{Working solutions}

All preparations were carried out using double distilled water, previously filtered through a $0.45 \mu \mathrm{m}$ filter paper.

\section{Stock standard solutions}

An accurately weighed $10.0 \mathrm{mg}$ of SPI and OTC were dissolved each in $100 \mathrm{~mL}$ water to give stock standard solutions with a concentration of $100.0 \mu \mathrm{g} \mathrm{mL}^{-1}$ for each compound.

\section{Linearity solutions}

Linearity solutions covering the concentration range from 4.0-36.0 and 2.0-32.0 $\mu \mathrm{g} \mathrm{mL}^{-1}$ for SPI and OTC, respectively, were prepared by appropriate dilution from the corresponding stock standard solutions. The spectrum of each individual solution was recorded in the range from 200 to $400 \mathrm{~nm}$ and stored in the computer. 


\section{METHODS}

\subsubsection{Linearity and Construction of Calibration Curves}

\subsubsection{Ratio difference method (RD)}

The recorded spectra of SPI are divided by the recorded spectrum of $32.0 \mu \mathrm{g} \mathrm{mL}^{-1}$ OTC and the difference in the amplitude of the ratio spectra (SPI/OTC) at 232 and $292 \mathrm{~nm}\left(\Delta \mathrm{P}_{232-292}\right)$ is plotted against the corresponding concentrations of SPI.

\subsubsection{Dual wavelength method (DWL)}

The SPI spectra are recorded and the difference between the absorbance at 232 and $375.5 \mathrm{~nm}$ was plotted against the corresponding concentration. Note: the difference between the absorbance at 232 and $375.5 \mathrm{~nm}$ is zero for OTC.

\subsubsection{Constant Value (CV) and Concentration Value (Conc. Value) of Oxytetracycline:}

In these methods the zero-order spectrum of the more extended component (OTC) was divided by the zero order normalized spectrum divisor of OTC $\left(1 \mu \mathrm{g} \mathrm{mL} \mathrm{mL}^{-1}\right)$; the constant was obtained from the plateau region which is related to the concentration of OTC. In the CV method the regression equation was computed relating the constant to OTC concentration, while for the Conc. Value there was no need for regression equation. The concentration is equal to the constant in the plateau region can be directly obtained from the graphical representation.

\subsubsection{Ratio Subtraction Constant Value (RS-CV) and Ratio Subtraction Concentration Value (RS- Conc. Value) of Spiramycin:}

The spectra of pure SPI were divided by its normalized spectrum divisor of SPI; the constant was obtained from the plateau region which is related to the SPI concentration. The calibration curve was constructed between the concentration and the corresponding constant for the (CV) method. While for (Conc. Value) the concentration can be directly obtained from the graphical representation.

\subsubsection{Application of the proposed methods for the determination of SPI and OTC in laboratory prepared mixtures}

Into a series of $10-\mathrm{mL}$ volumetric flasks, aliquots of SPI and OTC were accurately transferred from the stock standard solutions with the ratios of 1:8, 1:4, 1:1, 8:1 and 4.5:8 for SPI and OTC, respectively. Afterwards, each flask was completed to the mark with water. The spectra of the prepared mixtures were recorded and stored in the computer.
For the Ratio Subtraction Constant Value (RS-CV) and Ratio Subtraction Concentration Value (RS-Conc. value) of Spiramycin, the recorded zero order spectra of the laboratory prepared mixtures were divided by the absorption spectrum of standard OTC $(32.0 \mu \mathrm{g} \mathrm{mL}-1)$ Then, the amplitudes in the plateau region at $\lambda 274-284$ $\mathrm{nm}$ (the constant) were recorded and subtracted from the obtained ratio spectra, respectively. Then, multiplying the obtained spectra by OTC $\left(32.0 \mu \mathrm{g} \mathrm{mL}^{-1}\right)$ to get the zero spectra of SPI and application of Constant Value (CV) and Concentration Value (Conc. value) methods.

For the other methods, applying the proposed methods, the concentrations of SPI and OTC in the prepared mixtures are calculated from the corresponding equations.

\subsubsection{Application of the proposed methods for the determination of SPI and OTC in pharmaceutical formulation}

An Accurately weighed $92.7 \mathrm{mg}$ of the Arcospirox powder equivalent to $10.0 \mathrm{mg}$ of OTC and $6.65 \mathrm{mg}$ SPI was transferred into $100-\mathrm{mL}$ volumetric flask, dissolved in $50 \mathrm{~mL}$ water and sonicated for $15 \mathrm{~min}$. Then, the flask was completed to the mark with water. Further dilution was carried out by transferring 1,2 and $3 \mathrm{~mL}$ into a series of $10-\mathrm{mL}$ volumetric flasks.

The solutions were subjected to the analytical methods which are described previously. The concentrations of SPI and OTC were calculated from the corresponding regression equations. For the (RS-CV) and (RS-Conc.V) methods, the procedure mentioned under analysis of laboratory prepared mixtures was used. The validity of the methods was assessed using the standard addition technique.

\section{RESULTS AND DISCUSSION}

SPI and OTC are widely used antibacterial veterinary. Most of antibacterial veterinary dosage forms are produced with combination of SPI and OTC. Direct spectrophotometric determination of SPI and OTC in a binary mixture is difficult due to the sever overlap of the spectra of the two compounds (Figure 2). Therefore, this work was developed to enable simultaneous determination of SPI and OTC in veterinary dosage forms.

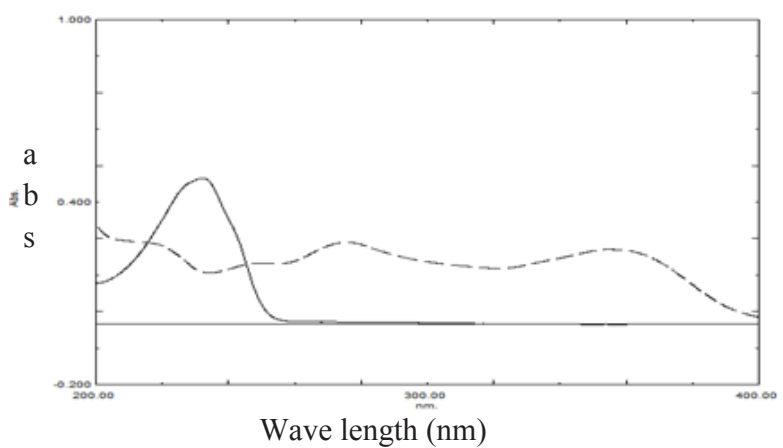

Fig 2: Zero order spectra of $20 \mu \mathrm{g} \mathrm{mL}^{-1}$ SPI (-) and $8 \mu \mathrm{g} \mathrm{mL}^{-1}$ OTC (---) recorded against water as blank. 


\subsection{Method development and optimization Ratio difference method (RD)}

The major factors affecting the ratio difference ${ }^{[25]}$ are the divisor concentration and the selected wavelength. The selected value for the divisor is a compromise between minimal noise and maximum sensitivity. Therefore, different concentrations including 4.0, 16.0 and 32.0 $\mu \mathrm{g} \mathrm{mL} \mathrm{mL}^{-1}$ of OTC as a divisor were tested. Satisfactory recovery, repeatability and signal to noise ratio were obtained with $32.0 \mu \mathrm{g} \mathrm{mL}^{-1}$ of OTC as a divisor. The second factor is the wavelengths at which the measurements are performed. Any two wavelengths can be selected provided that they exhibit difference in the amplitude of the ratio spectrum, and a good linearity is present at each wavelength individually.

The values of amplitude at 232 and $292 \mathrm{~nm}$ were chosen for determination of SPI in presence of OTC. The best results were obtained with OTC concentration of 32.0 $\mu \mathrm{g} \mathrm{mL} \mathrm{m}^{-1}$ as a divisor (Figure 3 ).

A linear relationship is obtained by plotting the differences in the amplitude at 232 and $292 \mathrm{~nm}$ against the corresponding concentration of SPI, The linear regression equation (1) is found to be

$$
\Delta \mathrm{P}=0.0337 \mathrm{C}-0.0005, \quad \mathrm{r}=0.9997
$$

Where $\Delta \mathrm{P}$ is the difference in the amplitude at 232 and $292 \mathrm{~nm}, \mathrm{C}$ is the concentration of SPI in $\mu \mathrm{g} \mathrm{mL}-1$ and $\mathrm{r}$ is the correlation coefficient.

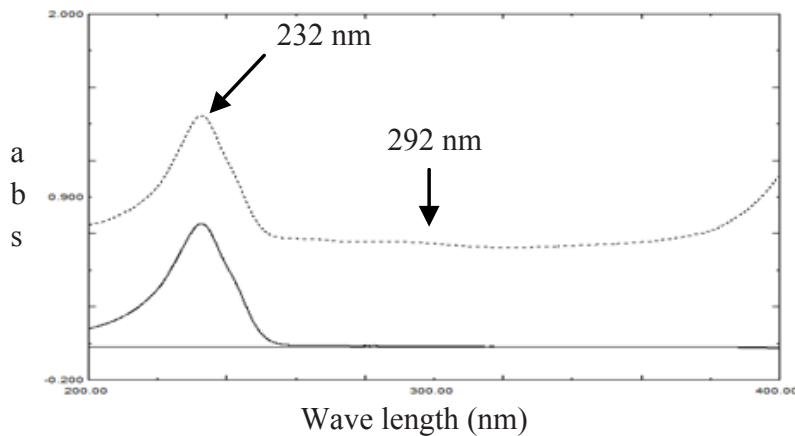

Fig. 3: Ratio spectra of $20.0 \mu \mathrm{g} \mathrm{mL} \mathrm{m}^{-1} \mathrm{SPI}(-)$, and a binary mixture of $20.0 \mu \mathrm{g} \mathrm{mL}^{-1}$ SPI and $20 \mu \mathrm{g} \mathrm{ml-1OTC} \mathrm{(---)} \mathrm{using} 32.0 \mu \mathrm{g} \mathrm{mL}^{-1}$ OTC as a divisor. The arrows showing the selected wavelengths.

\section{Dual wavelength method (DWL)}

The dual wavelength method depends on the difference in the absorbance at two wavelengths on the spectra which is directly proportional to the component of interest and independent of the interfering component.

The requirement for dual wavelength method is the selection of two wavelengths where the interfering component shows the same absorbance while the component of interest shows significant difference in absorbance. (Figure 4) shows that OTC has the same absorbance at
232 and $375.5 \mathrm{~nm}$, whereas, SPI has significant difference in the absorbance at these two wavelengths. Calibration graph was constructed and the concentration of SPI can be calculated from the following regression equation (2):

$$
\Delta \mathrm{A}=0.0242 \mathrm{C}-0.001, \quad \mathrm{r}=0.9998
$$

Where $\Delta \mathrm{A}$ is the absorbance difference at 232 and $375.5 \mathrm{~nm}, \mathrm{C}$ is the concentration of SPI in $\mu \mathrm{g} \mathrm{mL}^{-1}$ and $\mathrm{r}$ is the correlation coefficient.

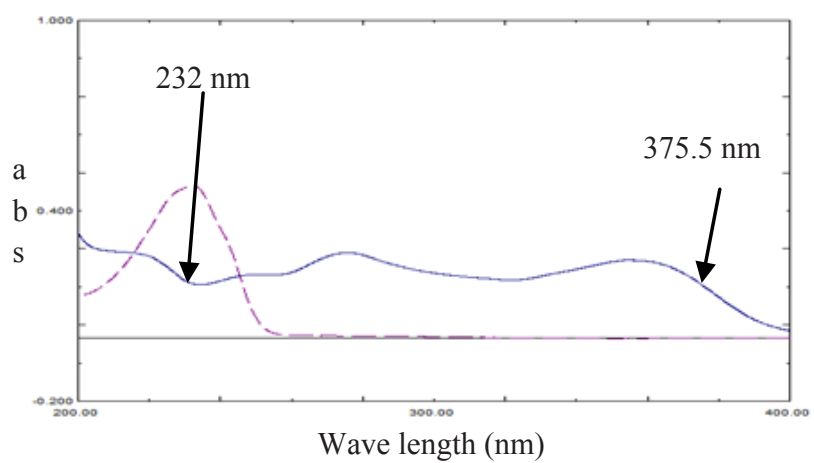

Fig. 4: Zero order absorption spectra of $20 \mu \mathrm{g} \mathrm{mL}^{-1}(---)$ SPI, and 8 $\mu \mathrm{g} \mathrm{mL}^{-1} \mathrm{OTC}(-)$. The arrows showing the selected wavelengths for dual wavelength calculations.

\section{$\square \quad$ Constant Value and Concentration Value for Oxytetracycline}

OTC spectrum is extended more than SPI as shown in (Figure 2). So that when the spectra of mixtures of OTC and SPI are divided by the spectrum of normalized divisor of OTC, a constant at the plateau region in the extended part of the spectrum $(250-400 \mathrm{~nm})$ was obtained as shown in (Figure 5).

This constant is equivalent to the concentration of OTC as it is resulting from dividing the spectra of the mixture by the normalized spectra of OTC of $1 \mu \mathrm{g} \mathrm{mL}^{-1}$.

$$
\begin{aligned}
& (\mathrm{SPI}+\mathrm{OTC}) / \mathrm{OTC}^{\prime}=\mathrm{SPI} / \mathrm{OTC}^{\prime}+\mathrm{OTC} \mathrm{OTC}^{\prime} \\
& (\mathrm{SPI}+\mathrm{OTC}) / \mathrm{OTC}^{\prime}=\mathrm{SPI} / \mathrm{OTC}^{\prime}+\text { constant }
\end{aligned}
$$

Where OTC ' is a normalized divisor with concentration of $1 \mu \mathrm{g} \mathrm{mL}^{-1}$.

For constant value method, a calibration curve between the constant and the corresponding concentration is constructed, where the concentration of OTC is obtained from regression equation (3):

$$
\text { Const. }=1.0001 \mathrm{C}-0.062, \quad \mathrm{r}=0.9999
$$

Where Const. is the constant at the plateau region (250-400 nm), C is the concentration of OTC in $\mu \mathrm{g} \mathrm{mL}^{-1}$ and $\mathrm{r}$ is the correlation coefficient.

While for Concentration Value method, the concentration was directly obtained from the spectra plateau region using that constant. The results of both methods were compared and both have good recoveries. 


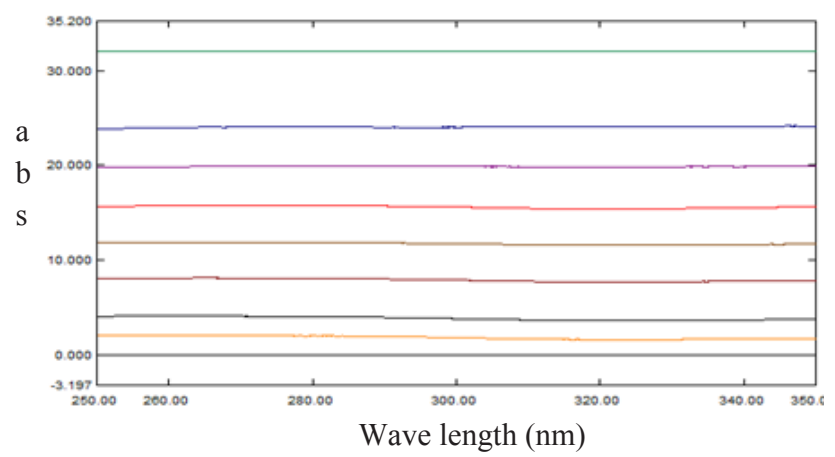

Fig. 5: The constant value obtained after the division of the zero order spectra of OTC $\left(2.0-32.0 \mu \mathrm{g} \mathrm{mL}^{-1}\right)$ by the spectrum of normalized $1.0 \mu \mathrm{g} \mathrm{mL}^{-1}$ OTC as divisor.

Ratio Subtraction (RS) Constant Value and Ratio Subtraction Concentration Value for Spiramycin:

SPI was resolved from OTC by RS according to the following equations:

$$
\begin{aligned}
& (\mathrm{SPI}+\mathrm{OTC}) / \mathrm{OTC}^{\prime}=\mathrm{SPI} / \mathrm{OTC}^{\prime}+\mathrm{OTC} \mathrm{OTC}^{\prime} \\
& \mathrm{SPI} / \mathrm{OTC}^{\prime}+\text { constant }- \text { constant }=\mathrm{SPI} / \mathrm{OTC}^{\prime} \\
& \mathrm{SPI} / \mathrm{OTC}^{\prime} \text { x OTC }^{\prime}=\mathrm{SPI}
\end{aligned}
$$

Then, the obtained spectra were divided by a normalized spectrum divisor of SPI. So, the constant obtained in the plateau region is related to SPI concentration as shown in (Figure 6).

For Constant Value, a calibration curve between that constant and the corresponding concentration was constructed and the concentration of SPI was obtained from the regression equation (4)

$$
\text { Const. }=1.0263 \mathrm{C}-0.1277, \quad \mathrm{r}=0.9997
$$

Where Const. is the constant at the plateau region $(225-245 \mathrm{~nm}), \mathrm{C}$ is the concentration of SPI in $\mu \mathrm{g} \cdot \mathrm{mL}^{-1}$ and $r$ is the correlation coefficient.
While for Concentration Value, the concentration is directly obtained from the spectra plateau region using that constant. The results of the two methods were compared and showed good recoveries.

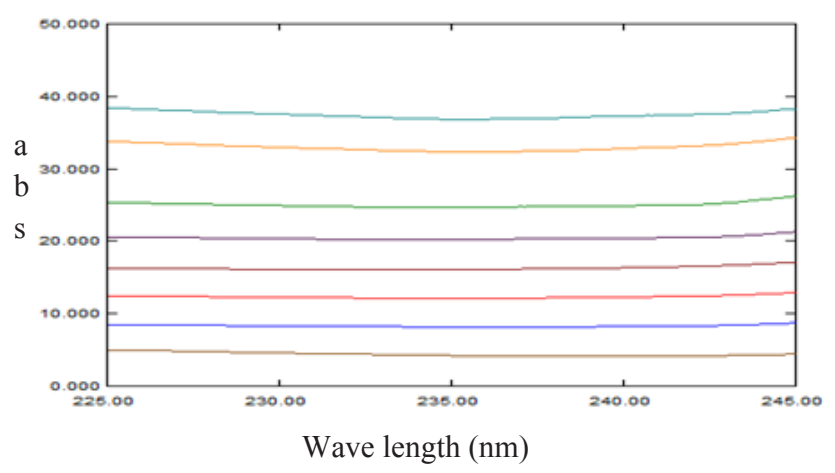

Fig. 6: The constant value obtained after the division of the zero order spectra of SPI $\left(4.0-36.0 \mu \mathrm{g} \mathrm{mL}^{-1}\right)$ by the spectrum of normalized $1.0 \mu \mathrm{g} \mathrm{mL}^{-1} \mathrm{SPI}$ as divisor.

\subsection{Method validation}

Methods validation has been performed according to ICH guidelines ${ }^{[26]}$.

\section{Linearity}

The linearity of the proposed methods is evaluated by analyzing eight different concentrations of standard solutions ranging from $4.0-36.0 \mu \mathrm{g} \mathrm{mL}^{-1}$ for SPI and from 2.0-32.0 $\mu \mathrm{g} \mathrm{mL}^{-1}$ for OTC in triplicates. The values of correlation coefficients are close to unity indicating good linearity, the regression equations are summarized in (Table 1).

\section{Range}

The calibration range was established by considering of the practical range necessary to Beer's law and the concentration of SPI and OTC present in the pharmaceutical preparations to give satisfactory accuracy, precision and

\begin{tabular}{|c|c|c|c|c|c|c|}
\hline \multirow[t]{2}{*}{ Parameters } & \multirow[t]{2}{*}{$(\mathrm{RD})$} & \multirow[t]{2}{*}{$(\mathrm{DWL})$} & \multicolumn{2}{|c|}{$(\mathrm{CV})$} & \multicolumn{2}{|c|}{ (Conc.value) } \\
\hline & & & SPI & OTC & SPI & OTC \\
\hline $\begin{array}{l}\text { Concentration range } \\
\left(\mu \mathrm{gL}^{-1}\right) \text { linearity }\end{array}$ & \multicolumn{2}{|c|}{$4.0-36.0$} & $4.0-36.0$ & $2.0-32.0$ & $4.0-36.0$ & $2.0-32.0$ \\
\hline Slope & 0.037 & 0.024 & 1.026 & 1.000 & --- & --- \\
\hline Intercept & 0.0005 & 0.001 & 0.128 & 0.062 & --- & --- \\
\hline Correlation coefficient ( $\mathrm{r}$ ) & 0.9997 & 0.9998 & 0.9997 & 0.9999 & --- & --- \\
\hline Accuracy (mean \pm S.D.) & $100.33 \pm 0.87$ & $99.95 \pm 1.16$ & $100.64 \pm 1.12$ & $100.39 \pm 1.09$ & $101.19 \pm 0.63$ & $99.68 \pm 0.99$ \\
\hline Repeatability $^{\mathrm{a}}$ & 1.51 & 1.54 & 0.61 & 0.35 & 0.61 & 0.68 \\
\hline Intermediate precision $^{\mathrm{b}}$ & 0.57 & 1.12 & 0.87 & 1.66 & 1.11 & 1.33 \\
\hline
\end{tabular}
linearity (Table 1).

Table 1: Validation resultsof the proposed spectrophotometric methods for the determination of Spiramycin (SPI) and Oxytetracycline $\mathrm{HCl}$ (OTC).

a The intraday $(\mathrm{n}=3)$, average of three different concentrations repeated three times within day.

$\mathrm{b}$ The interday $(\mathrm{n}=3)$, average of three different concentrations repeated three times in three successive days. 


\section{Selectivity}

The selectivity of the proposed methods is assessed by the analysis of six different laboratory prepared mixtures containing different ratios of SPI and OTC; satisfactory results were obtained and presented in (Table 2).

Table 2: Determination of Spiramycin (SPI) and Oxytetracycline $\mathrm{HCl}$ (OTC) in laboratory prepared mixtures by the proposed methods.

\begin{tabular}{|c|c|c|c|c|c|c|c|c|}
\hline \multirow{3}{*}{$\begin{array}{l}\text { No. of } \\
\text { mixtures }\end{array}$} & \multirow{2}{*}{\multicolumn{2}{|c|}{ Claimed conc. taken in $\mu \mathrm{g} \mathrm{mL}^{-1}$}} & \multirow{3}{*}{$\begin{array}{c}\text { (RD) } \\
\text { \% Recovery }{ }^{*} \\
\text { SPI }\end{array}$} & \multirow{3}{*}{$\begin{array}{c}\text { (DWL } \\
\% \text { Recovery }{ }^{*} \\
\text { SPI }\end{array}$} & \multicolumn{2}{|c|}{$(\mathrm{CV})$} & \multicolumn{2}{|c|}{ (Conc.value) } \\
\hline & & & & & \multicolumn{2}{|c|}{$\%$ Recovery $^{*}$} & \multicolumn{2}{|c|}{$\%$ Recovery $^{*}$} \\
\hline & SPI & OTC & & & SPI & OTC & SPI & OTC \\
\hline 1 & 4.0 & 32.0 & 98.31 & 101.24 & 100.24 & 100.36 & 101.87 & 100.18 \\
\hline 2 & 8.0 & 32.0 & 100.17 & 101.23 & 100.10 & 99.99 & 101.13 & 99.81 \\
\hline 3 & 16.0 & 16.0 & 101.47 & 99.10 & 101.52 & 98.88 & 100.05 & 98.5 \\
\hline 4 & 20.0 & 20.0 & 101.96 & 98.69 & 100.49 & 99.42 & 100.25 & 99.13 \\
\hline 5 & 32.0 & 4.0 & 99.79 & 98.85 & 99.15 & 100.11 & 101.36 & 98.58 \\
\hline 6 & 36.0 & 8.0 & 100.04 & 99.68 & 100.85 & 99.14 & 100.14 & 98.37 \\
\hline
\end{tabular}

* Average of three determinations.

\section{Accuracy}

The accuracy of the results was studied by applying the proposed methods for determination of five different samples of SPI and OTC. The accuracy is presented in (Table 1).

To ascertain the accuracy of the proposed methods, recovery studies are carried out by standard addition technique at three different levels (Table 3).

\section{Precision}

The precision was studied by applying the proposed methods for determination of three different concentrations of each of SPI and OTC, which were analyzed three times intra-daily for repeatability and inter-daily on three different days for intermediate precision. The precision results are summarized in (Table 1).

Table 3: Determination of Spiramycin (SPI) and Oxytetracycline $\mathrm{HCl}$ (OTC) in their pharmaceutical formulation by the proposed methods and application of standard addition technique

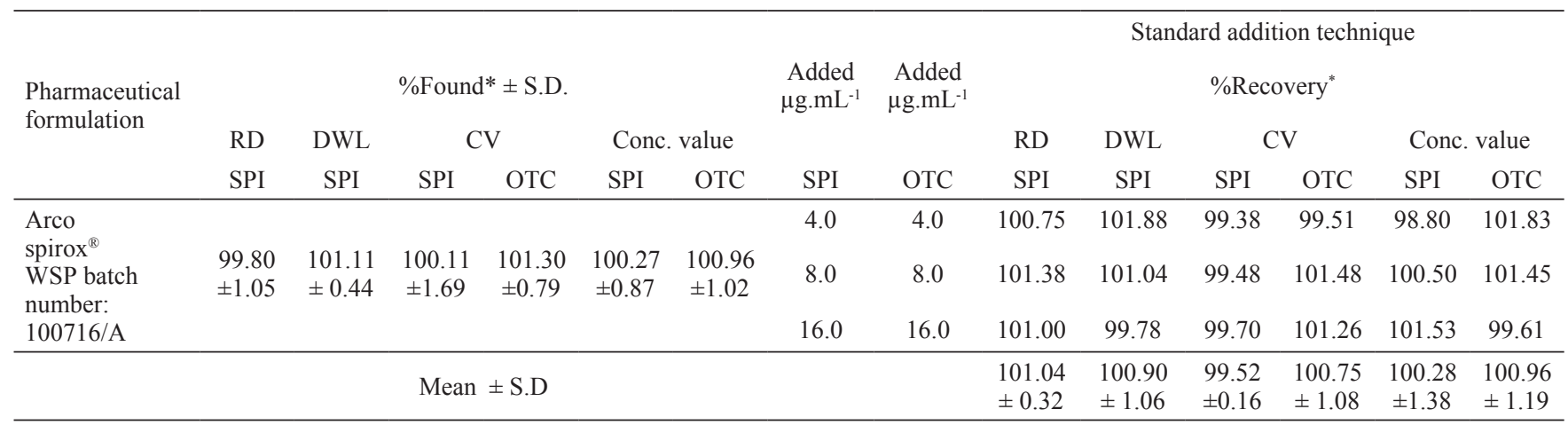

Average of three determinations.* 


\section{Statistical analysis}

Results obtained by the proposed methods for determination of pure SPI and OTC are statistically compared with those obtained by applying the reported methods $^{[10,13]}$. The calculated $\mathrm{t}$ - and $\mathrm{F}$-values are found to be less than the theoretical ones, confirming accuracy and precision at $95 \%$ confidence level (Table 4 ).

Table 4: Statistical comparison of the results obtained by applying the proposed methods and published methods

\begin{tabular}{|c|c|c|c|c|c|c|c|c|}
\hline \multirow[t]{3}{*}{ Parameters } & \multirow{2}{*}{$\begin{array}{c}\mathrm{RD} \\
(\mathrm{SPI})\end{array}$} & \multirow{2}{*}{$\begin{array}{l}\text { DWL } \\
(\mathrm{SPI})\end{array}$} & \multicolumn{2}{|c|}{$\mathrm{CV}$} & \multicolumn{2}{|c|}{ Conc. value } & \multicolumn{2}{|c|}{ Reported methods ${ }^{[10,13}$} \\
\hline & & & (SPI) & (OTC) & (SPI) & (OTC) & $(\mathrm{SPI})^{\mathrm{b}}$ & $(\mathrm{OTC})^{\mathrm{c}}$ \\
\hline & 100.33 & 99.95 & 100.64 & 100.39 & 101.19 & 99.68 & 100.09 & 99.48 \\
\hline \multicolumn{9}{|l|}{ Mean\% } \\
\hline $\begin{array}{c}\text { S.D. } \\
\mathrm{n}\end{array}$ & 0.87 & 1.16 & 1.12 & 1.09 & 0.63 & 0.99 & 1.03 & 0.88 \\
\hline \multirow{4}{*}{$\begin{array}{c}\text { Variance } \\
\text { Student's t-test } \\
\quad(2.132)^{\mathrm{a}} \\
\text { F-test }(6.39)^{\mathrm{a}}\end{array}$} & 0.76 & 1.35 & 1.25 & 1.18 & 0.39 & 0.98 & 1.06 & 0.77 \\
\hline & 0.69 & 0.84 & 0.21 & 0.29 & 0.16 & 0.75 & - & - \\
\hline & & & & & & & & \\
\hline & 1.39 & 1.27 & 1.17 & 1.53 & 2.72 & 1.27 & - & - \\
\hline
\end{tabular}

a The values in parenthesis are the corresponding theoretical values of $\mathrm{t}$ and $\mathrm{F}$ at $(P=0.05)$.

b charge transfer complex between SPI and quinalizarin producing charge transfer complex in methanolic medium $\Delta \lambda=568 \mathrm{~nm}$.

c HPLC method using mobile phase; methanol-0.01 M oxalic acid, pH 3.0 (30:70, v/v) at 250 nm using a Silasorb C8 column.

\section{CONCLUSION}

This work provides four different spectrophotometric methods for the simultaneous analysis of SPI and OTC in veterinary dosage forms. The developed Concentration Value method could determine both drugs without the use of regression equations; this was attained directly from the graphical representation. The proposed methods do not need any sophisticated apparatus or any preliminary separation steps and can be easily applied in quality control laboratories for the determination of SPI and OTC in presence of each other in veterinary pharmaceutical formulation.

\section{CONFLICT OF INTEREST}

There are no conflicts of interest.

\section{REFERENCES}

1. Martindale: The Complete Drug Reference. thirtyeights ed. Vol. 1. 2014, London: Pharmaceutical Press.

2. Clarke's Analysis of Drugs and poisons third ed. Vol. 2. 2004, london: Pharmaceutical Press.

3. British pharmacopoeia Commission. British pharmacopoeia Vol. veterinary. 2018, Stationery Office: London. 102,103.

4. C. Civitareale, M. Fiori, A. Ballerini, G. Brambilla, Identification and quantification method of spiramycin and tylosin in feedingstuffs with HPLC-UV/DAD at $1 \mathrm{ppm}$ level, Journal of Pharmaceutical and Biomedical Analysis 36 (2004) 317-325. https://doi.org/10.1016/j. jpba.2004.06.010.

5. Q. Lin, G. Kahsay, T. de Waal, P. Zhu, M. Tam, R. Teughels, W. Wang, A. Van Schepdael, E. Adams, Improved liquid chromatographic method for quality control of spiramycin using superficially porous particles, Journal of Pharmaceutical and Biomedical Analysis 149 (2018) 57-65. https://doi.org/10.1016/j. jpba.2017.10.041.

6. H.M. Maher, R.M. Youssef, R.H. Khalil, S.M. ElBahr, Simultaneous multiresidue determination of metronidazole and spiramycin in fish muscle using high performance liquid chromatography with UV detection, Journal of chromatography. B, Analytical technologies in the biomedical and life sciences 876 (2008) 175-181. 10.1016/j.jchromb.2008.10.033.

7. C. Sagan, A. Salvador, D. Dubreuil, P.P. Poulet, D. Duffaut, I. Brumpt, Simultaneous determination of metronidazole and spiramycin I in human plasma, saliva and gingival crevicular fluid by LC-MS/ MS, Journal of Pharmaceutical and Biomedical Analysis 38 (2005) 298-306. https://doi.org/10.1016/j. jpba.2004.12.033.

8. M.A. García Mayor, G. Paniagua González, R.M. Garcinuño Martínez, P. Fernández Hernando, J.S. Durand Alegría, Synthesis and characterization of a 
molecularly imprinted polymer for the determination of spiramycin in sheep milk, Food Chemistry 221 (2017) 721-728. https://doi.org/10.1016/j. foodchem.2016.11.114.

9. M.M. Elkhoudary, R.A. Abdel Salam, G.M. Hadad, Comparative artificial neural network and partial least squares models for analysis of Metronidazole, Diloxanide, Spiramycin and Cliquinol in pharmaceutical preparations, Spectrochimica Acta Part A: Molecular and Biomolecular Spectroscopy 130 (2014) 222-229. https://doi.org/10.1016/j. saa.2014.04.002.

10. R. El Sheikh, A.A. Gouda and K.M. Khalil, Sensetive and selective spectrophotometric determination of Spiramycin in pure form and in pharmaceutical formulations, IJPSR 4 (2013) 2234-2243.

11. R. Fernandez-Torres, M.O. Consentino, M.A.B. Lopez, M.C. Mochon, Simultaneous determination of 11 antibiotics and their main metabolites from four different groups by reversed-phase high-performance liquid chromatography-diode array-fluorescence (HPLC-DAD-FLD) in human urine samples, Talanta 81 (2010) 871-880. https://doi.org/10.1016/j. talanta.2010.01.031.

12. C. Nebot, M. Guarddon, F. Seco, A. Iglesias, J.M. Miranda, C.M. Franco, A. Cepeda, Monitoring the presence of residues of tetracyclines in baby food samples by HPLC-MS/MS, Food Control 46 (2014) 495-501. https://doi.org/10.1016/j. foodcont.2014.05.042.

13. I.N. Papadoyannis, V.F. Samanidou, L.A. Kovatsi, A rapid high performance liquid chromatographic (HPLC) assay for the determination of oxytetracycline in commercial pharmaceuticals, Journal of Pharmaceutical and Biomedical Analysis 23 (2000) 275-280. https://doi.org/10.1016/S07317085(00)00300-9.

14. G.T. Peres, S. Rath, F.G.R. Reyes, A HPLC with fluorescence detection method for the determination of tetracyclines residues and evaluation of their stability in honey, Food Control 21 (2010) 620-625. https://doi. org/10.1016/j.foodcont.2009.09.006.

15. H. Sanderson, F. Ingerslev, R.A. Brain, B. HallingSørensen, J.K. Bestari, C.J. Wilson, D.J. Johnson, K.R. Solomon, Dissipation of oxytetracycline, chlortetracycline, tetracycline and doxycycline using HPLC-UV and LC/MS/MS under aquatic semi-field microcosm conditions, Chemosphere 60 (2005) 619-629. https://doi.org/10.1016/j. chemosphere.2005.01.035
16. M.C. Vargas Mamani, F.G. Reyes Reyes, S. Rath, Multiresidue determination of tetracyclines, sulphonamides and chloramphenicol in bovine milk using HPLC-DAD, Food Chemistry 117 (2009) 545552. https://doi.org/10.1016/j.foodchem.2009.04.032.

17. H. Yu, Y. Tao, D. Chen, Y. Wang, Z. Yuan, Development of an HPLC-UV method for the simultaneous determination of tetracyclines in muscle and liver of porcine, chicken and bovine with accelerated solvent extraction, Food Chemistry 124 (2011) 1131-1138. https://doi.org/10.1016/j.foodchem.2010.07.024.

18. W.Naidong, S. Geelen, E. Roets, J.Hoogmartens, Assay and purity control of oxytetracycline and doxycycline by thin-layer chromatography - a comparison with liquid chromatography, Journal of Pharmaceutical and Biomedical Analysis 8 (1990) 891-898. https://doi. org/10.1016/0731-7085(90)80138-F.

19. W. Naidong, S. Hua, E. Roets, J. Hoogmartens, Assay and purity control of tetracycline, chlortetracycline and oxytetracycline in animal feeds and premixes by TLC densitometry with fluorescence detection, Journal of Pharmaceutical and Biomedical Analysis 33 (2003) 85-93. https://doi.org/10.1016/S07317085(03)00153-5.

20. J.M. Lemus Gallego, J. Pérez Arroyo, Spectrophotometric determination of hydrocortisone, nystatin and oxytetracycline in synthetic and pharmaceutical preparations based on various univariate and multivariate methods, Analytica Chimica Acta 460 (2002) 85-97. https://doi. org/10.1016/S0003-2670(02)00138-1.

21. F. Salinas, A. E. Mansilla, J.J. Berzas Nevado, Simultaneous determination of sulfathiazole and oxytetracycline in honey by derivative spectrophotometry, Microchemical Journal 43 (1991) 244-252. https://doi.org/10.1016/S0026265X(10)80012-8.

22. C. Yarnitzky, W.F. Smyth, Square wave polarographic and voltammetric analysis of selected electroreducible drugs, International Journal of Pharmaceutics 75 (1991) 161-169. https://doi.org/10.1016/03785173(91)90190-Y.

23. A.O. El Demerdash, M. M. Fouad, H. F. El Sanabary, S.A. Abdel Razeq, Densitometric and UV-Spectrophotometric Methods for Simultaneous Determination of Spiramycin adipate in Binary Mixture with Oxytetracycline- $\mathrm{HCl}$ or Tetracycline$\mathrm{HCl}$, International Research Journal of Pure \& Applied Chemistry 17 (2018). 
24. R. Magdy, et al., Determination of amlodipine and atorvastatin mixture by different spectrophotometric methods with or without regression equations. Spectrochimica Acta Part A: Molecular and Biomolecular Spectroscopy, 2019. 210: p. 203-211.

25. E. Elzanfaly, A. Saad, A.-E. B Abd-Elaleem, A Novel Simple Method for Resolving Overlapped Spectral
Data with A Wide Range of Applicability, and Its Application as a Stability Indicating Method for Determination of Tazarotene, Pharmaceut Anal Acta (2012) 153-156. 10.4172/2153-2435.1000153.

26. ICH Q2A. validation of analytical methods. International Conference on Harmonization. 2003, IFPMA: Geneva. 